\title{
Las memorias holográficas como nuevo soporte de documentos audiovisuales
}

\author{
Lola García Santiago *
}

Artículo recibido:

1 de agosto de 2005.

Artículo aceptado:

21 de noviembre de 2005.

\section{RESUMEN:}

Frente a los actuales soportes ópticos y magnéticos que pueden almacenar información en la superficie del material sensible utilizado, la holografía ha revolucionado los conceptos de grabación y almacenamiento. A pesar de las cuatro décadas que lleva existiendo esta tecnología, es aún poco conocida y su forma de operar constituye un misterio. Este artículo da a conocer la técnica del almacenamiento holográfico y la situación actual, así como el potencial de las memorias holográficas en el campo de la información y la documentación.

Se presentan las múltiples ventajas que posee la memoria holográfica y sus inconvenientes, que se tratan de solventar experimentando con diversos mecanismos y nuevos soportes de grabación.

* Universidad de Granada, España. mdolo@ugr.es

INVESTIGACIÓN BiBLIOTECOLÓGICA, Vol. 20, Núm. 41, julio/diciembre, 2006, México, ISSN: 0187-358X. pp. 141-160 
Descriptores: Memorias holográficas; almacenamiento holográfico de datos; soportes de información; documentación.

\author{
ABStract \\ Holographic memories as new format for storing au- \\ diovisual documents \\ Lola García Santiago
}

Compared to the actual optical and magnetic supports which can store information on the surface of receptive materials, holography has completely changed the concepts of recording and storage. Although this technology has existed for decades it is almost unknown and the way it operates remains a mystery. This paper describes the holographic storage technique and its potential in the field of information and documentation. Its multiple advantages are outlined as well as some present problems.

Keywords: Holographic memories; Holographic data storage; Information formats; Documentation.

\title{
INTRODUCCIÓN
}

T os programas y sistemas que trabajan con documentos audiovisuales Lobligan a que las mejoras en el campo del almacenamiento documental se centren en conseguir dispositivos más rápidos y de mayor capacidad.

Los discos magnéticos, los discos ópticos y las memorias de semiconductores (por ejemplo el láser azul) son soportes que tienen en común su bidimensionalidad y almacenan la información en su superficie. La nueva generación de sistemas de almacenamiento conlleva la alternativa de utilizar la holografía como una tecnología capaz de almacenar en tres dimensiones, externa e internamente.

Se trata también de una tecnología óptica, es decir se utiliza el rayo láser como elemento de grabación, pero con características específicas que la diferencian de las tradicionales [Johnson \& Briggs, 1971]. Estos sistemas que todavía dominan el mercado, empiezan a tener dificultades para aumentar su 
capacidad de almacenamiento y mantener una velocidad de acceso razonable. Para solventar este problema se han venido "comprimiendo" los datos o, lo que es lo mismo, codificando los datos en una cantidad menor de bits para ahorrar espacio y tiempo de transmisión. Como este sistema obliga a utilizar un programa específico para comprimir y descomprimir, la velocidad de grabación se ralentiza y el tiempo de acceso aumenta.

Pero para que un sistema multimedia sea eficaz, necesita dispositivos de gran capacidad de almacenamiento, fáciles de manipular, versátiles para todo tipo de usos o archivos (desde presentaciones multimedia hasta programas informáticos), de rápido acceso, de bajo costo y de consumo reducido. Todas estas razones presentan al almacenamiento holográfico como una sólida alternativa.

No nos extenderemos demasiado es cuestiones técnicas, sino en las ventajas que la holografía nos ofrece a los profesionales de la información y la documentación, y en conocer la limitaciones que tiene por ahora la holografía.

\section{LA HOLOGRAFÍA: QUÉ ES}

La técnica óptica consiste en registrar la imagen de un objeto mediante la intersección de dos haces sobre el rayo láser, que se aplican sobre el sujeto, lo bañan ortogonalmente y le informan sobre sus dimensiones tridimensionales. Las interferencias producidas se plasman de manera redundante sobre la superficie y en el interior de un soporte o volumen (generalmente fotopolímeros o cristal).

\section{El proceso holográfico de almacenamiento de datos}

En los sistemas más básicos, el rayo de luz del láser fuente pasa a través de un separador de rayos que lo divide en dos, un rayo de objeto (en este caso de datos) y otro de interferencia [García-Santiago, 2005]. El rayo de interferencia se usa para crear el patrón de interferencia que se dirige a través de un conducto que incluye un rotor de polarización y un sistema de refracción hacia las páginas [Li,1994]. Por otro lado, el rayo de objeto o de datos pasa por un sistema óptico que se expande sobre una superficie denominada "componedor de páginas", que funciona como un modulador de luz espacial (en inglés, SLM). Los datos digitales se sobreimpresionan sobre el rayo expandido utilizando este SLM. Las imágenes aparecen oscuras o claras dependiendo del valor de los datos digitales. Desde el componedor de páginas el rayo de datos sufre la transformación de Fourier y posteriormente se enfoca 
en la estructura cristalizada que alberga el holograma. Es aquí donde los dos rayos convergen y producen un determinado patrón de interferencia que se graba sobre un material foto-refractivo. Esto a su vez, modifica las propiedades ópticas del material de cristal con un patrón de carga electrónico. Se pueden grabar en un solo cristal muchos hologramas cambiando el ángulo de incidencia de los rayos sobre este cristal.

Cuando se procede a la recuperación o reconstrucción del holograma, se aplica únicamente el rayo de referencia. El cual incide sobre la página que se desea leer. El rayo ilumina el modelo de interferencia donde se encuentran los puntos claro-oscuros.

Estos puntos se interpretan a través de otro dispositivo que los transforma en datos electrónicos digitales [Shandle, en Soussan].

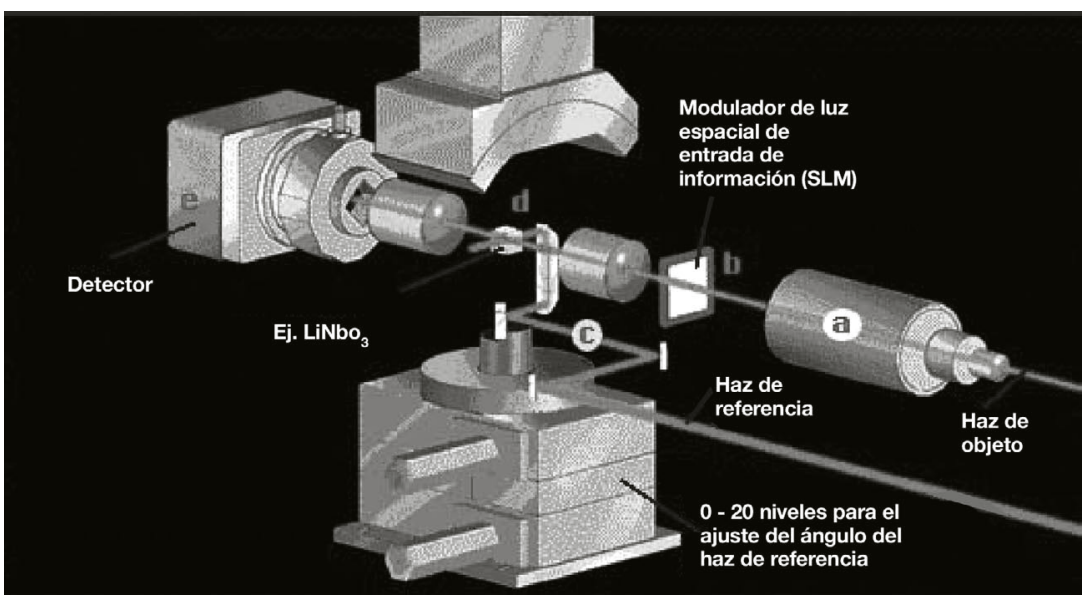

Figura 1: Grabación de datos holográficos

Fuente: Holographic Memory http://www.doc.ic.ac.uk/ nd/surprise_97/journal/vol1/ary/holo.html

VENTAJAS E INCONVENIENTES DE LA HOLOGRAFÍA

Las ventajas más destacadas que ofrece la holografía son:

\section{La capacidad de almacenamiento}

Utilizando un sistema holográfico para el almacenamiento de datos se podrían guardar $10 \mathrm{~Gb}$ de datos en un centímetro cúbico (frente a los $100 \mathrm{~Kb}$ por centímetro cuadrado de los soportes magnéticos). Para hacernos una idea, un soporte del tamaño de un terrón de azúcar almacenaría miles de páginas. 


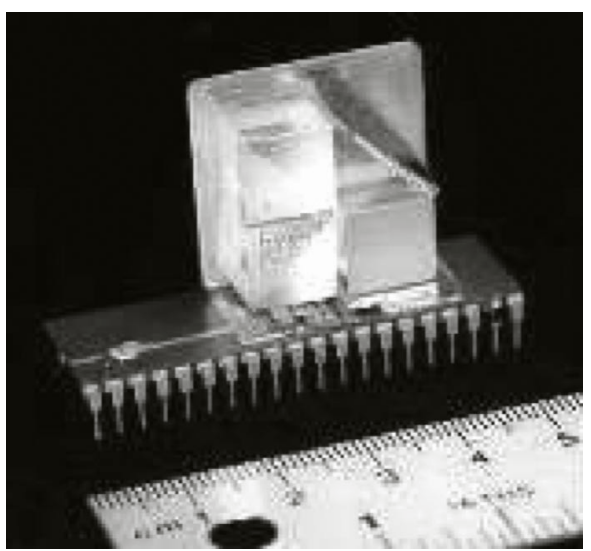

Fig. 2: Memoria holográfica modular compacta (Psaltis)

Fuente: Chuang E, Liu WH, Drolet JJP, Psaltis D Holographic random access memory (HRAM) en: P IEEE 87(11): 1931-1940 nov 1999Accesible en: http://optics.caltech.edu/Publications/Papers/Chuang HRAm.pdf

- Además de la alta densidad para almacenar [Lerner \& Adams, 1983] información (ya hemos comentado que excede los 108 bytes por pulgada cuadrada o, lo que es lo mismo, un holograma de 4x6 pulgadas puede almacenar unos 2xlos 108 bits de información en 20000 hologramas individuales) cuenta con otras ventajas como dispositivo de almacenamiento.

- Tiene también la capacidad de albergar imágenes en tres dimensiones

- La imagen reconstruida es tridimensional al haber quedado registradas las diferencias de camino óptico entre las ondas emitidas por los distintos puntos del objeto; y goza de una gran profundidad, característica que no depende de la distancia de observación con el punto objeto de la imagen que se reproduce [García-Santiago: 2000].

- Permite guardar ficheros de grandes dimensiones como suelen serlo los ficheros multimedia (texto, imagen y sonido).

\section{La velocidad de acceso}

Con el almacenamiento holográfico hablamos de acceder a la información en milisegundos, y otras de sus cualidades son:

- La selección aleatoria de información.

- Sus posibilidades de transferencia, que permiten la recuperación paralela de información en un intervalo de tiempo puede llegar a $1 \mathrm{~Gb}$ por segundo. 
- Su acceso paralelo; es decir, la posibilidad de colocar la información de la manera que se quiera y de obtenerla a la misma velocidad. Se toma una cadena de bits de golpe, de una sola vez, y que funciona como una gran banda ancha. Un ejemplo sería una película o varias. El hecho de poner una película es secuencial pero si se ponen diez a la vez ya no lo es.

- Rápida recuperación de los datos por su capacidad de multiplexación [García-Santiago, 2000].

\section{La permanencia}

Desde el punto de vista de la documentación permanente destacamos lo siguiente:

- Almacenamiento permanente de los datos. Es decir, la grabación se realiza de una sola vez y esto es muy útil para copias de seguridad.

- La redundancia: la imagen se registra uniformemente por todo el holograma (distribución uniforme de lo grabado). Esto ayuda a proteger la información registrada de los errores debidos al polvo y a los arañazos por lo que se reduce el deterioro del conjunto [Johnson y Briggs, 1971], y se puede consultar lo grabado incluso en parte del holograma.

- No necesita sistemas ópticos, lo que evita la aparición de distorsiones y aberraciones.

- Permite sobreimpresionar varios hologramas sin interferirse ni perjudicarse (multiplexación). Esta característica trae consigo otras ventajas:

- Gran banda ancha, puesto que puede contener información en canales individuales.

- Bajo costo de almacenamiento.

- Exhaustividad: con lo que un holograma almacena toda la información visual que emana de un objeto. Esas ondas de luz se mueven esféricamente, de forma contextual, como el sonido que se crea en un concierto. Siguiendo con el símil, igual que se pueden oír la mayoría de los sonidos juntos, también se pueden ver todos los detalles de un objeto en un soporte holográfico (film, cubo, etc.).

A continuación un cuadro comparativo que presenta, a modo de resumen, las diferencias entre los distintos sistemas de almacenamiento. Sólo la memoria temporal o memoria RAM es más rápida en cuanto a tiempo de acceso $(160 \mathrm{Mb} / \mathrm{seg}$.) y tiene mayor tasa de transferencia que los dispositivos holográficos, pero carece de la capacidad para almacenar permanentemente. 
Tabla 1: Cuadro comparativo Fuente: [Boyles, 2000]

\begin{tabular}{|l|c|c|c|c|}
\hline $\begin{array}{c}\text { Tipo de } \\
\text { almacenamiento }\end{array}$ & Capacidad & $\begin{array}{c}\text { Tiempo de acceso } \\
\text { (En Mseg) }\end{array}$ & $\begin{array}{c}\text { Tasa de transferencia } \\
\text { (En Mb/seg) }\end{array}$ & Grabación/Lectura \\
\hline $\begin{array}{l}\text { Disco duro } \\
\text { (magnético) }\end{array}$ & 60 a $100 \mathrm{~Gb}$ & 10 & 15 & $\begin{array}{c}\text { Cabezas mecánicas en } \\
\text { superficie magnética }\end{array}$ \\
\hline DVD & $5 \mathrm{~Gb}$ & 150 & 2 & $\begin{array}{c}\text { Uso del láser sobre } \\
\text { la superficie }\end{array}$ \\
\hline Holograma & $200 \mathrm{~Gb}$ & 2 & 50 ' & $\begin{array}{c}\text { Interferencia del láser en } \\
\text { todo el material }\end{array}$ \\
\hline
\end{tabular}

Pero la holografía todavía tiene que resolver algunas cuestiones pendientes. Se está investigando cómo conseguir un equilibrio entre la funcionalidad del rayo de referencia y su tamaño, demasiado grande aún si se piensa desde un punto de vista comercial.

El otro punto débil son los materiales de grabación. Existen dificultades para conseguir cristales y fotopolímeros de gran tamaño y/o espesor. En el caso de los cristales se exige que ese tamaño vaya acompañado de una buena calidad óptica [Boyles, 2000].

Otras desventajas que tienen los actuales productos de almacenamiento holográfico son:

\section{El precio}

- Alto costo comercial, que lo hace todavía no competitivo.

- Es una nueva herramienta que sustituiría a las anteriores sin posibilidad de compatibilidad.

- Su capacidad de almacenamiento y reproducción sin pérdida de calidad vendrán dadas por el tipo de material. Debe no ser volátil para que el holograma perdure.

- El material utilizado debe ser económicamente competitivo (carestía del producto).

\section{La regrabación}

- No es posible actualizar datos sin regrabar todo el holograma. La técnica holográfica no permite modificar sólo una parte del holograma dada su característica de redundancia. No hay que olvidar que todo lo registrado en el soporte tiene intensidad, ángulo y forma de grabación, no se puede regrabar por partes. Este inconveniente se está solventando con los hologramas multiplexados. No obstante, se sigue trabajando en la obtención de grabadoras y reproductores holográficos que tengan un tamaño y un precio competitivos en el mercado. 
- Por su novedad, todavía no hay normas que regulen los soportes de grabación holográficos ni que permitan el intercambio entre instrumentos de grabación.

\section{Aplicaciones}

La capacidad de almacenar datos en cualquier formato, estático y en movimiento, abre para los hologramas numerosas aplicaciones relacionadas con el mundo de la documentación. Como documentos capaces de albergar información, la holografía es especialmente útil para determinadas temáticas. Un ejemplo de esto es la NTT (Nippon Telephone E Telegraph) que desarrolló una tecnología holográfica para grabar 30 horas de imágenes en movimiento en un soporte de cristal del tamaño de una uña [Enteleky, 2003]. Y también el trabajo realizado por el MIT Media Lab Spatial Imaging Group, que trabaja con el holovideo (video electro-holográfico) en tiempo real. Entre otros aspectos este equipo trabaja, desde 1990, programas para mejorar el holovideo y la compresión holográfica de banda ancha para transmitir a través de red [Lucente, 1998]. En medicina, antropología y arquitectura, la holografía se utiliza tanto para el diseño como para la muestra de maquetas [Orazem, 1992].

Otras posibles aplicaciones de los sistemas holográficos de almacenamiento de datos serían las comunicaciones de satélite, el reconocimiento de transmisiones aéreas, las bibliotecas digitales de alta velocidad, el almacenamiento masivo para vehículos tácticos y el procesamiento de imágenes para propósitos médicos, militares y/o de video.

\section{Prototipos de sistemas holográficos de información}

Los esfuerzos llevados a cabo, desde los comienzos hasta el presente, nos muestran la evolución tecnológica y el interés que existe por almacenar holográficamente la información.

Durante la década de los 70 se tuvo una orientación documental más definida (sustitución de microformas por hologramas, almacenamiento de documentación cartográfica,etc.). A partir de los años 80 importa más el formato de la información (imagen, sonido, etc.). El objetivo es almacenar holográficamente todo tipo de información. Ya en los 90, la holografía se utilizó para todo tipo de sistemas de seguridad y autentificación.

- La biblioteca holográfica. Considerada como la biblioteca del futuro, este proyecto de la década de los 70 tuvo lugar en Tianjin Microform 
Technique Corporation, y constaba de un ordenador y un scanner pequeño para fichas. El scanner mostraría, imprimiría y enviaría información bibliográfica de la ficha a través del ordenador. El problema era el costo. Era necesario desarrollar técnicas para obtener fichas, a gran escala y más baratas, y también un lector de libros informático.

- Prototipo HrmR (Human Read/Machine Read) [Maugh,1979 en Nelson]. Propuesto en la empresa Harris-Intertype Corp., de Melbourne. Se trata de un subsistema del sistema de memoria masiva de microfilm que combina el almacenamiento holográfico de datos digitales y de imágenes en el mismo medio. Estas características, junto con la capacidad y densidad de almacenamiento, permitían guardar y recuperar información cartográfica [Nelson, Vander Lugt y Zech, 1974].

- Sistema de recuperación de información holográfico. Esta experiencia soviética tuvo lugar a finales de los años 70 y demostró que se reducía el tiempo de búsqueda y que era asequible para el usuario. Las descripciones que elaboraba el VINITI mensualmente se almacenaban holográficamente. La búsqueda se realizaba a través de matrices holográficas, de manera similar a como se hacían las fichas perforadas, y se grababan en microhologramas. Estas matrices enlazaban con los datos de localización de los documentos incluidos en el fichero inverso.

- Almacenamiento holográfico para el reconocimiento óptico de huellas digitales. Se está llevando a cabo en el National Institute of Standards and Technology (NIST). Las huellas digitales se graban mediante un SLM (Spatial Light Modulator) y se transforman mediante el método Fourier en hologramas tridimensionales. Posteriormente, y a través de una red neuronal, se diferencian las huellas con un proceso de coincidencia muy minucioso.

Todos estos experimentos utilizaban en mayor o menor medida la holografía. Pero realmente no se puede hablar de un almacenamiento holográfico sino hasta la década de los 90.

- Sistema digital total de Stanford (1994). Se trata del primer sistema completamente automatizado de almacenamiento holográfico de datos, concretamente de imágenes, con banda sonora. Se demostró que podían usarse componentes electrónicos y ópticos del mercado, y se aplicó una nueva técnica de codificación que procesaba las señales digitales de manera que se reducía el "ruido" y aumentaba la capacidad de almacenamiento [Heanue en Orlov 2000].

La naturaleza de la tolerancia del ruido en el almacenamiento holográfico de datos nace para subsanar los problemas asociados con las fuentes de ruido. Además, fue el primer estudio efectuado sobre tasas 
de error en la transferencia de datos (ruido). Este sistema se componía de un medio de almacenamiento que, consistía en un cristal de litio niobado con una película de hierro. Se dividía la superficie en $C$ ejes en un ángulo de 45 grados. Como los hologramas grabados con anterioridad podían borrarse con los que se grabaran después, se incluyó un esquema de grabación que permitía almacenar de manera eficiente un gran número de páginas con una difracción igual. La técnica de codificación consistía en escribir una secuencia de pixeles off-on en el SLM para representar el 0, y de on-off para el 1.

- Sistema completamente automatizado Siros [InPhase] Fue ésta la primera demostración de un sistema de almacenamiento holográfico controlado completamente de manera electrónica y automática. La arquitectura electrónica del sistema se basó en un tecnología de bus y un conjunto de herramientas reprogramables denominadas, manera lógica, "puertas programadas por campo" (FPGA, Field-Programmable Gate Array).

Una vez que se ha demostrado que la grabación, recuperación y organización de información almacenada en hologramas son posibles, la investigación se centra fundamentalmente en las unidades y soportes de lectura y escritura de esos hologramas y en la manera de procesar y codificar los datos para su grabación.

\section{TIPOS DE MEMORIAS HOLOGRÁFICAS}

Una vez conocida la técnica de la holografía aplicada al almacenamiento de datos ¿cómo puede ésta aplicarse al campo de la información y la documentación? No se trata de la imagen de un libro, sino de su contenido. Para ello nos aprovechamos de la capacidad de la holografía para almacenar objetos tridimensionales.

Todo sistema holográfico de grabación se basa en la multiplexación, que permite incluir en un mismo soporte o volumen más de un holograma; utiliza una de las características del almacenamiento holográfico, la recuperación asociativa.

Si se buscaran en un dispositivo de almacenamiento convencional todos los registros que comparten una determinada característica, recuperaríamos el registro en la RAM, y la búsqueda se realizaría con un programa de aplicación que miraría en todos y cada uno de los documentos. Con el almacenamiento holográfico, este proceso puede llevarse a cabo en la propia memoria. 
En lugar de reconstruir páginas de datos con un rayo de referencia, el patrón de datos que nos interese se coloca en el SLM, y se enfoca al punto de almacenamiento concreto con el haz de señal. Todos los rayos de referencia se usan para almacenar los hologramas de esa pila, y se reconstruyen. La intensidad de cada rayo es proporcional a la correlación entre el patrón de datos original almacenado y el patrón de datos del rayo de señal que examina. Una vez que el haz de referencia enfoca, en un "plano de correlación", a un conjunto, el ángulo del haz de referencia será el que corresponda para que puedan identificarse los hologramas pertinentes. El rayo de referencia puede reconstruir los hologramas fuera de la cámara. El proceso de búsqueda y recuperación puede durar unos 5 milisegundos.

Ahora bien, el sistema de multiplexación utilizado es lo que diferenciará los tipos de memorias holográficas [Psaltis, 2001].

\section{Memoria de acceso aleatorio holográfico (HRAM)}

En las HRAM (Holographic Random-Access Memory), los rayos de referencia y de datos (objeto) se dirigen a un volumen que contiene múltiples localizaciones de almacenamiento. Los rayos ópticos se dirigen muy rápidamente con escáneres ópticos no mecánicos, la mayoría de estos los cuales utilizan un deflector acústico-óptico o un SLM de cristal líquido unidimensional. Un sistema HRAM puede leer hologramas desde cualquier localización en una secuencia esencialmente aleatoria.

La fotosensibilidad de la mayoría de los cristales fotorefractivos es relativamente baja, por lo que la velocidad de grabación está ligeramente por debajo que la de lectura. Además, resulta casi imposible cambiar el estado de un solo pixel de un holograma. Se podría sustituir un determinado holograma dentro de una pila de hologramas, pero el proceso no es sencillo.

Por lo tanto, un sistema HRAM no es realmente un sistema de memoria de lectura-escritura, sino más bien una memoria de un borrado y múltiples lecturas.

Este sistema se ajusta a aquellas aplicaciones que requieran almacenar gran cantidad de datos casi permanentes y con una alta rapidez de lectura y transferencia. Algunos ejemplos serían, el al macenamiento de películas, copias de servidores web.

Un inconveniente del sistema es que el número de localizaciones a las que tiene acceso está limitado a la óptica de la dirección del rayo láser. 


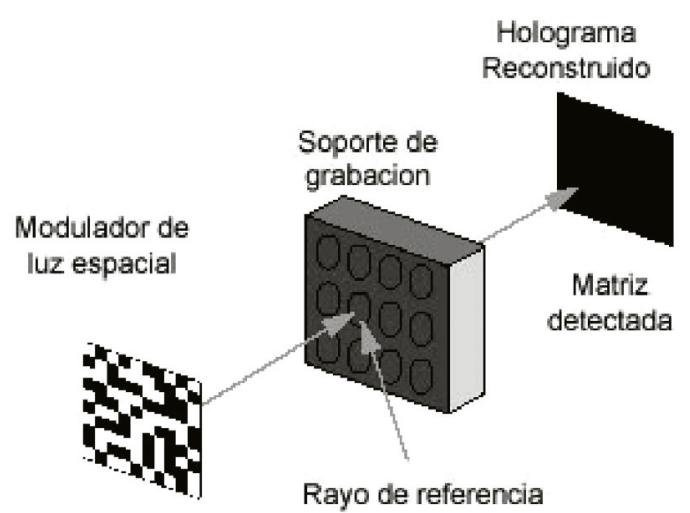

Fig. 3: HRAM. Fuente: Ashley, et al, "Holographic Data Storage", en IBM Journal Research Development vol. 44, n.3, mayo 2000, p. 341-368 Accesible en: http://www.research.ibm.com/journal/rd/443/ashley.pdf (Último acceso 31 de mayo de 2005)

\section{Memoria holográfica modular compacta}

Se trata de una alternativa que mejora los sistemas HRAM. La memoria holográfica modular compacta toma el mismo conjunto de pixeles para la grabación y la recuperación, en el y del soporte de grabación. Se dirige a la misma localización volviendo sobre los pasos de la trayectoria que ha seguido el rayo láser, lo que devuelve la dirección original de la señal, al SLM. Esto permite utilizar lentes más baratas o incluso no tener que utilizarlas. Si cada píxel del SLM es a la vez modulador y detector lumínico, todo el dispositivo de almacenamiento se podría reducir y elaborar sin partes móviles y se compondría de varios módulos (ver figura 4).

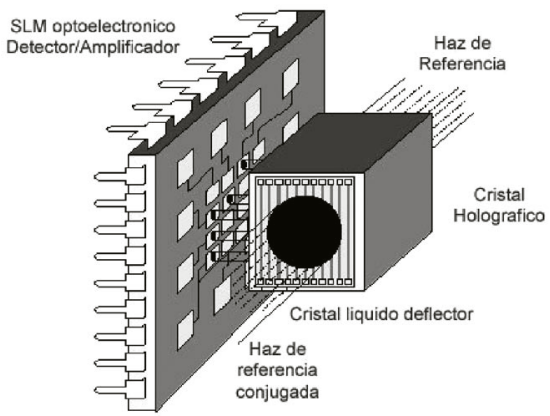

Fig. 4: Memoria holográfica modular compacta 
Cada modulo tiene un aspecto parecido a una memoria RAM, pero con la sutil diferencia de que puede almacenar 25 hologramas, según demostraron en la empresa Caltech. Para contrarrestar la erosión en el cristal fotorefractivo, se le añade a cada píxel la orden de que, periódicamente, detecte y refresque los hologramas. Esto permitiría que el sistema fuera más flexible y no obligara a tener hologramas de manera permanente, y se podrían borrar hologramas de un grupo de ellos.

En un sistema modular, el costo por megabyte depende de un conjunto de pixeles "inteligentes" y dos ángulos compactos dirigidos (uno para el haz de escritura y otro para el de lectura). Se puede recuperar de manera asociativa, pero hay que añadirle otro detector por módulo aumentando el número de pixeles mientras se mantiene el costo del conjunto detector y el ángulo baja, lo cual es la clave para poner en marcha esta arquitectura.

\section{Discos holográficos $3 D$}

Esta opción se centra más en los materiales de almacenamiento. El disco se compone de una capa de un milímetro de espesor. Los hologramas se almacenan en cada ubicación de la superficie del disco. Estas localizaciones se organizan a lo largo de las pistas radiales. Con el movimiento del cabezal se selecciona la pista y la rotación del disco le da acceso a cada pista.

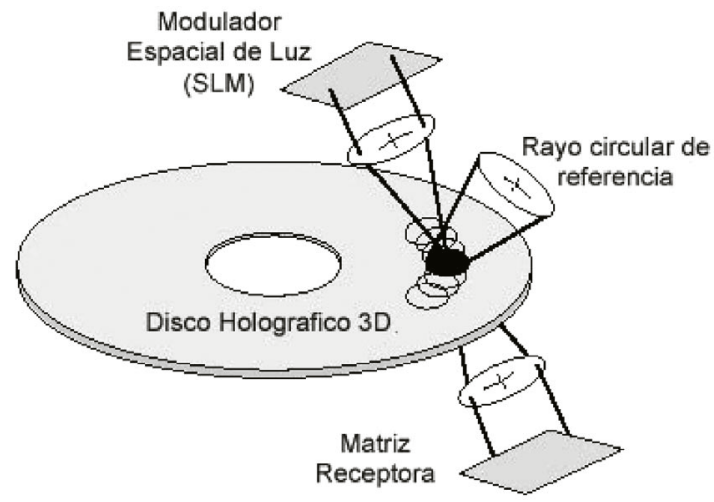

Fig. 5: Discos holográficos 3D (Psaltis)

Fuente: Psaltis D, Burr GW, "Holographic data storage”, en COMPUTER31 (2): 52-+FEB 1998 http://optics.caltech.edu/Publications/Papers/Burr\%20Holo\%20Data\%20Storage.pdf

Se puede utilizar la multiplexación por ángulo en los hologramas multiplexados sobre un disco holográfico, igual que en la arquitectura HRAM. No 
obstante, el escáner de ángulo necesitaría un cabezal de lectura muy grande y pesado como para poder obtener un acceso rápido a los hologramas de las diferentes pistas radiales. Para que esto no pase, se puede utilizar un rayo convergente o esférico como rayo de referencia. Esto permitiría tener un rayo de referencia de ángulos simultáneamente en todas las pistas, y no de una en una. Esto aumentaría sensiblemente la velocidad de lectura.

Además los discos holográficos permiten sistemas de lectura y regrabación o de solo lectura. En el primer caso, los sistemas WORM incorporan un SLM convirtiendo el cabezal de lectura en uno de lectura/escritura. En este caso el proceso de grabación se basa en las reacciones químicas de los fotopolímeros, que son el material de grabación de los discos 3D.

Las aplicaciones ROM son similares a las de la HRAM, películas, audio, juegos de ordenador y demás información de sólo lectura [Psaltis, 2001].

El cuadro siguiente compara estas técnicas; sin embargo, hay que hacer constar que se trata de prototipos que aún están en fase de experimentación y mejora.

Tabla 2: HRAM y Discos 3D

\begin{tabular}{|l|l|l|l|l|}
\hline $\begin{array}{c}\text { Memorias } \\
\text { holográficas }\end{array}$ & $\begin{array}{c}\text { Capacidad de } \\
\text { almacenamiento }\end{array}$ & $\begin{array}{l}\text { Velocidad } \\
\text { de lectura }\end{array}$ & $\begin{array}{c}\text { Velocidad } \\
\text { de acceso }\end{array}$ & \multicolumn{1}{|c|}{ Aplicaciones } \\
\hline HRAM & Terabytes & $\begin{array}{l}1 \text { Gbits por } \\
\text { segundo }\end{array}$ & $\begin{array}{l}\text { Bloques de } 50 \text { a } \\
100 \text { Gb }\end{array}$ & Video y grandes servidores web \\
\hline Discos 3D & $\begin{array}{l}100 \text { Gbytes por } 120 \\
\text { mm. de disco }\end{array}$ & $\begin{array}{l}\text { Más de } 500 \\
\text { Mbits por } \\
\text { segundo }\end{array}$ & $\begin{array}{l}\text { Bloques de } 100 \\
\text { Mb en } 10 \text { a } 100 \\
\text { milisegundos }\end{array}$ & $\begin{array}{l}\text { Archivo de datos definitivos } \\
\text { pero de acceso rápido (ej. } \\
\text { Datos médicos, mapas de alta } \\
\text { resolución, imágenes de satélite, } \\
\text { películas, multimedia, programas } \\
\text { de ordenador) }\end{array}$ \\
\hline
\end{tabular}

Fuente: Psaltis 2001

\section{Discos Holográficos Versátiles (HVD)}

Parten de los hologramas de color [García-Santiago, 2000] y los estudios sobre ellos han variado, al igual que las compañías investigadoras. InPhase se funda en el año 2000 con la fusión de las empresas Lucent Technologies Venture, New Venture Partners LLC, Signal Case, Madison Dearborn Patners, Hitachi Maxwell Ltd., Imation Corporation y New Technology Partners. InPhase debía mostrar su sistema holográfico de grabación de video Tapestry a finales de 2003. Se espera que las capacidades de almacenamiento en los discos Tapestry de una sola escritura, alcancen los $100 \mathrm{~Gb}$, con una tasa de transferencia de $20 \mathrm{Mbps}$ [11]. 
La empresa japonesa Optware ha conseguido la primera grabación y reproducción del mundo, de películas en un disco holográfico transparente y quiere sacar al mercado HVD (Holographic Versatile Disc) Players, Readers y Writers en el año 2006 para el uso de las grandes empresas. Unas versiones más baratas saldrán al mercado en el 2007. La empresa ha desarrollado un sistema holográfico colineal de almacenamiento de datos, que utiliza un láser verde de 532 nano-metros para poder leer los datos holográficos de un disco de $12 \mathrm{~cm}$. Los dos rayos, el de referencia y el del objeto, interfieren entre sí dentro de la capa de grabación del disco y guardan los datos. Debajo de esa capa hay otra capa más, pre-formateada, que guarda los datos servo y que se lee con un láser rojo. Esto permite hacer un seguimiento preciso del disco.

Entre la capa de datos y la de servo se encuentra un espejo que refleja el láser verde, pero que es transparente para el láser rojo. Este espejo es capaz de parar la disipación de la luz dentro del disco, que podría causar un aumento en el ruido y baja calidad de la señal.

Para las empresas estos aparatos costarán aproximadamente 20000 dls. e inicialmente se utilizaran HVD de 200 Gb, que costarán 100 dls. cada uno.

\section{Sistema de lectura de 1 Gb y 100 Mb de capacidad, de Stanford y Siros}

Para los medios con espesor (p. ej. el litio niobado), la capacidad geométrica de los 90 grados está limitada, generalmente, por la dinámica y el ruido del soporte más que por las interferencias de la multiplexación. En cambio los medios planos (ej. los fotopolímeros), no tienen esta limitación y el número de hologramas que se pueden superponer en una localización está determinado por el número de grados de libertad disponibles para la multiplexación. Un multiplexación angular en la geometría de transmisión no permite una suficiente densidad de almacenamiento de los datos, por lo que son necesarias otras técnicas de multiplexación. Por eso DARPA fundó el consorcio PRISM que ha utilizado medios de almacenamiento con espesor (también denominados volúmenes) y grabado con láser pulsado, con lo que ha obtenido grandes logros, junto con los esfuerzos de la empresa Polaroid y su filial Aprilis. Y para grabar, mientras el disco estaba en constante rotación, se presentó una nueva técnica de multiplexación basada en un rayo de referencia que modula su fase.

Este sistema se compone de una cámara de video digital y un visualizador de cristal líquido IBM que le sirven como detectores, más un componedor de páginas. Un disco holográfico de fotopolímero está en constante rotación en un eje, sobre el que recibe los pulsos. Con la sincronicación electrónica, se pueden dirigir las diferentes posiciones angulares; las radiales necesitan un dispositivo que mueva el disco y el eje verticalmente [Orlov, 2000]. 


\section{El Tratamiento documental de los hologramas}

Toda la documentación artístico-músical, médica, química, arquitectónica, etcétera, ha conseguido aprovecharse de las ventajas de la tridimensionalidad que permite la holografía. Ya en los años 60 se vio el potencial educativo de la holografía, lo que motivó a Upatnieks y Leith del Departamento de Ingeniería eléctrica de la Universidad de Michigan y al Instituto de Investigación Medioambiental de Michigan (ERIM), a construir el primer modelo de lector de hologramas bibliotecario. Éste, parecido a una televisión o a un lector de microformas, constaba de una pantalla en la que aparecía la imagen localizada en la película. El rayo láser de baja potencia se refleja fuera de los espejos de la caja para reconstruir la imagen virtual que se encuentra almacenada en la película dentro de la caja. Así, da la sensación de que el objeto se encuentra tras la pantalla.

Desde la perspectiva del tratamiento de hologramas, la conservación vendrá totalmente determinada por el soporte material, los que hemos considerado en este artículo como los que se encuentran aún en fase muy experimental. Otra posibilidad es que se trate de un electroholograma, en cuyo caso estaríamos hablando de datos generados y almacenados por ordenador. Para su organización, conservación y recuperación, hay que tener en cuenta otros aspectos. En su descripción formal se consignará el tipo de onda utilizada para la grabación, el tipo de soporte holográfico, el tipo de holograma, si es master u original, y entre otras características. D’Alleyrand elaboró en 1977 ciertas reglas de catalogación para la Biblioteca de Investigación del Museo de la Holografía y tras la clausura del museo en 1992, la colección y el trabajo de catalogación pasaron al MIT. Para la entrada principal, si el holograma no es el resultado de una técnica innovadora y tampoco trata de un tema original, su entrada se hará por título. En cualquier otro caso el encabezamiento principal será la nueva técnica o el/la autor/a del holograma. En estos casos el soporte material del holograma era todavía una película y no el ya comentado cubo, con excepción del caso del ICG. Aunque sin referencia explícita, también las Anglo-American Cataloging Rules (AACR II) permiten hacer referencia en notas a reproducciones holográficas en caso de documentación musical y describir éstas realizando adaptaciones (Harrassowitz).

Para la clasificación de los hologramas, OCLC propuso en 1988 unas normas para materiales bidimensionales y tridimensionales. Dentro de la categoría " $r$ " de artefactos tridimensionales y objetos que aparecen en forma real, se encuentra concretamente en el subgrupo " $\mathrm{r}$ " de objetos naturales.

Para la recuperación tanto de hologramas como de electrohologramas, ya a finales de la década de los 70 y principios de los 80 se da la solución en la 
antigua U.R.S.S [Zakharchenko, 1980] mediante la organización de ficheros inversos. Estos sistemas de información holográficos están constituidos por un grabador y equipo gráfico con un procesador electrónico. El equipo gráfico o visualizador holográfico está conectado con el procesador electrónico para buscar y posteriormente visualizar las holografías. El sistema de información holográfico mantiene un sistema de ficheros inversos con los números de orden de todos los documentos del archivo y las coordenadas para localizar cada holograma en el archivo de imágenes holográficas. Para realizar la búsqueda mediante descriptores, el fichero inverso localiza los números de orden que responden a un determinado descriptor y de ahí pasa a la localización en el fichero de imágenes holográficas. En este caso se recupera uno o varios hologramas en el soporte físico; una mejora a este sistema sería el uso de hologramas generados por ordenador lo que permitiría una mayor rapidez no ya de localización sino de recuperación y visión.

\section{Futuro}

Compañías arraigadas como Sony, IBM, NASA, etcétera, ya utilizan esta técnica para mejorar la localización y recuperación de información y así obtener más y mejores imágenes. Empresas como Aprillis, Bell-Labs, InPhase... son ejemplos del interés que ya ha despertado la holografía, y muestran los esfuerzos que las empresas están haciendo para obtener resultados que ya empiezan a llegar al mercado.

\section{Conclusiones}

El almacenamiento holográfico puede ofrecer muy interesantes posibilidades y promete ser la solución más efectiva a nivel de costo, para las exigencias de almacenamiento de archivos multimedia o de cualquier otra nueva tecnología. Esta nueva tecnología óptica permite almacenar información digital, como los hologramas tridimensionales; También almacenar y recuperar los datos como patrones bidimensionales de luz, o páginas, en un volumen tridimensional de cristal sensible a la luz, y proporcionan la base de la tecnología del almacenamiento holográfico. Los datos se organizan en páginas en lugar de en bits individuales, y con el uso de las capas se consigue mayor velocidad y un menor control por parte del sistema operativo del ordenador. Esto significa que es muy factible manejar el control de un sistema operativo de disco, y que puede controlarse la demanda informática para gestionar imáge- 
nes o multimedia. Esta tecnología se basa en las técnicas de almacenamiento holográfico de volúmenes fotorefractivos (PVHS); es decir, utiliza luz en lugar de electricidad, como con la fibra óptica, lo que la hace extremadamente rápida y un medio potencialmente portátil. Los aparatos de almacenamiento holográfico serían una buena elección para los sistemas que necesitan acceso aleatorio rápido para grabar y mostrar un video digital, y para sistemas de procesamiento y transacción de alto rendimiento a bajo costo, pues permite acceso rápido a la información almacenada.

Habrá que saber cómo conservar, catalogar y clasificar hologramas en las bibliotecas del futuro, un futuro cada día más presente. Los datos holográficos no supondrán tanto problema en relación con su tratamiento puesto que se trata de documentos digitales en formato audiovisual, textual, etcétera, pero sí en relación con su cantidad. Disponemos de un medio para almacenar grandes volúmenes de información, con acceso rápido y en formato 3D, que servirá para realizar búsquedas de información en bases de datos voluminosas y consecuentemente las bases de datos que consultemos también cambiarán e incluirán descriptores, texto completo y diferentes objetos (por ejemplo, huellas digitales).

La transformación también tendrá lugar en el campo de la edición electrónica con revistas, enciclopedias, mapas y hasta video juegos, en los que las memorias holográficas harán que estos productos sean aun más potentes. Las posibilidades multimedia con un soporte holográfico están menos limitadas por la velocidad de acceso a los datos, las transferencias y el almacenamiento.

Los discos holográficos pueden llegar a ser los sustitutos del DVD, pero todavía se carece del material fotopolímero que tenga un espesor suficiente. Pese a todo, las memorias holográficas y su tecnología son indudablemente las candidatas a ser la nueva generación de sistemas de almacenamiento, sobre todo ahora que se están consiguiendo grandes avances en lo que a materiales holográficos se refiere. Como el logrado por el Lawrence Berkeley National Laboratory (LBNL), la Universidad de California y el Instituto de Microelectrónica de Madrid (IMM) del Consejo Superior de Investigaciones Científicas que ha conseguido que las memorias holográficas sean también regrabables.

Cada vez necesitamos almacenar más cantidad de información, sobre todo si estas copias de seguridad incluyen a todo lo que se encuentra en Internet. Los archivos electrónicos pueden verse desbordados sin la existencia de nuevos sistemas de almacenamiento cada vez más pequeños y potentes.

Es un hecho que en breve plazo en el mundo de la documentación, la holografía va a ser de gran ayuda a la hora de almacenar información, aunque de momento, no se haya podido resolver el tema de grabar terabytes y hasta petabytes en un soporte holográfico y hacer modificaciones posteriores. 


\section{BiBLIOGRAFÍA}

Aprilis Japan's Optware dadvances holographic disc storage http://www.thic.org/pdf/Jul03/aprilisinc.draguin.pdf (Último acceso 12/12/2004)

Ashley, J. et al. "Holographic Data Storage”. IBM Journal of Research and Development, Vol 44, No 3, 2000, pp 341-368

http://www.research.ibm.com/journal/rd/443/ashley.html (Último acceso 16/11/2001)

Boyles "Holographic Memory", Stephanie Boyles, CSI 3300, April 12, 2000 http://ucsu.colorado.edu/ stephanb/projects/CSI3300.htm (Último acceso 16/11/2001)

Chuang E, Liu Wh, Drolet Jjp, Psaltis D "Holographic random access memory (HRAM)” P IEEE 87 (11): 1931-1940 nov. 1999 Accesible en:

http://optics.caltech.edu/Publications/Papers/Chuang HRAM.pdf

Enteleky "Holography in imaging and video" En:

http://www.enteleky.com/holography/mhol1.htm (Último acceso: $23 / 09 / 2003$ )

García-Santiago, Lola "La holografía en el mundo de la documentación”, El Profesional de la Información; 9 (4) Apr 2000, p.20-31

"La holografía hoy. Nuevos documentos del futuro" Quaderns Digitals. Net: El portal de la Educación; n. 39, Junio 2005

Gestión de Documentos Electrónicos http://www.century.com.py/EDM.doc (Último acceso 12/05/2004)

Heanue, J F, M C Bashaw y L Hesselink 1994 "Volume holographic storage and retrieval of digital data” Science, 1994, p. 265-749, cit. en: Orlov, Sergei S. "Volume holographic data storage" Association for Computing Machinery. Communications of the ACM. New York: Nov 2000. Vol. 43, Iss. 11; p. 46-55

Holographic Memory http://www.doc.ic.ac.uk/ nd/surprise_97/journal/vol1/ary/holo.html

InPhase http://www.inphase-technologies.com/

Johnson, C; Briggs, E "Holography as applied to information storage and retrieval systems" Journal of the American Society for Information Science; 22 (3) May June 71, 187-192

Kallender, Paul “Japan's Optware advances holographic disc storage: Each disc could store as much as $200 \mathrm{~GB}$ of data" En: ComputerWorld August 24, 2004

http://www.computerworld.com/hardwaretopics/storage/story/0,10801,95446,00.html

Lerner, Rita G., et al, "Primary publication systems and scientific text processing" en: Annual Review of Information Science and Technology, volume 18, edited by Martha E. Wliams, New York, Knowledge Industry for American Society for Information Science, 1983 128-149. bibliog. 
Li, Hsin-Hu, Photorefractive 3D Disks for optical data storage and artificial neural networks [Tesis doctoral] Sydney 1994

Lin, Hai, Tsaipei Wang y Thomas W. Mossberg, Ieee OCT 1995 'Spectral Holographic Memory at 8 Gbit/in 2', Department of Physics, University of Oregon, IEEE Lasers and Electro-Optics Society, Newsletter, Vol. 9, p.10 (Oct. 1995). (Último acceso 16/11/2001). http://opticb.uoregon.edu/ mosswww/memory/shm.html (Último acceso 16/11/2001)

Lucente, Mark "Interactive three-dimensional holographic displays: seeing the future in depth". IBM Research Division. http://alumni.media.mit.edu/ lucente/pubs/CG97/

Maugh,-T.-H.---II "Holographic filing: an industry on the verge of birth" IEEE-Transactions-on-Professional-Communications. March 1979; PC-22(1): 34-6

Nelson, R.h.; Vander Lugt, A. y Zech R. G. "Holographic data storage and retrieval" Optical Engineering, vol. 13, Sept.-Oct. 1974, p. 429-434.

Orazem, Vito "Holography as an element of the media architecture," SPIE Vol. 2333 (1995), International Symposium on Display Holography, pp. 168-177.

, "Holography as a material for light: Radical Holography," SPIE Vol. 1600 (1992), International Symposium on Display Holography, pp. 160-165;

Orlov, Sergei S. "Volume holographic data storage", en Association for Computing Machinery. Communications of the ACM. New York: Nov 2000. Vol. 43, Iss. 11; p. 46-55

Psaltis D, Burr Gw "Holographic data storage" COMPUTER 31 (2): 52-+ FEB 1998 Accesible en:

Http://optics.caltech.edu/Publications/Papers/Burr\%20Holo\% 20Data\%20Storage.pdf

Psaltis, Demetri y Fai Mok "Holographic Memories" Scientific American, November 1995 vol. 273 , No. 5 p. $70-76$

http://optics.caltech.edu/publications/SciAm-Nov1995/article. html (Último acceso 16/11/2001)

Shandle, Jack ( 1993, September 16). " Mass Storage looks for new solutions” Electronic Design, pp. 93 - 103. En SOUSSAN: http://www.enteleky.com/holography/biblio.htm

Soussan, Michael "Holographic Storage Technology: A Viable Solution To The Mass Storage Requirements Of Multimedia Computing" En: HoloQuest http://www.enteleky.com/holography/mpaper.htm

Tena, Juan "Científicos españoles desarrollan memorias "holográficas" con capacidad de regrabación” ImásD: correo de ciencia y tecnología, 12 de noviembre de 2000 http://www.imasd-tecnologia.com/imasd/nov00/1100ti1.htm 